\title{
PRÁTICA EDUCATIVA E FORMAÇÃO DE PROFESSOR
}

Andrêa Maruano Longavez *

\section{Resume:}

Em linhas gerabis, o artige prowa situr a formacho de protessores no cenario educacional

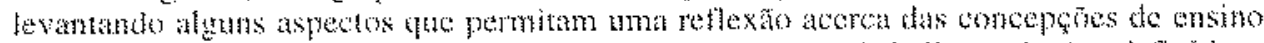

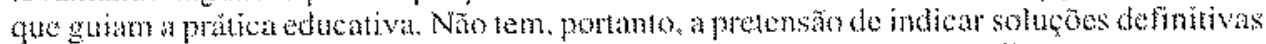

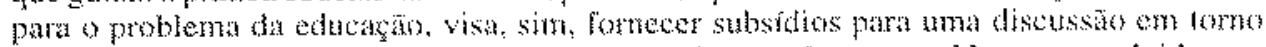

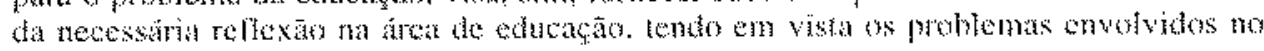

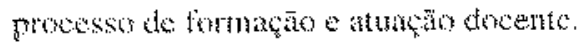

\section{Palavras-Chave:}

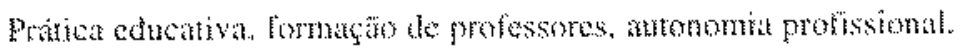

\section{Prática educativa e coneepçôes de ensino}

A escola vem, em sua matoria, trabalhando os conhedmentos socialmente construidos conro fatos isolados, conceitos estaticos previanente estabelecidos polos currículos e tossilizados nos livros didálicos. Essa prática educativa ignora. entre outras coisas, as experiencias vividas pelos alunos, os significados dos contecimentos abordados nu escola seus vinculos com tma pritica social global.

En conseguência, observa-se, com frequèncha, que a escola está almentando no aluno habib de reproduzir formulas, textos, conceitos, etc, deixando de pensar aspectos importantes no processo edncativo, tais como idéias, porquês, significados. relaçoses, entre outros. Nesse sentido, o aluno canaliza sua atenço prefencialmente para a descoberta de mecanismo a ser milizado ma resoluço de uma situngân problema decodificando, automaticamente, uma deteminada questäo sem se preocupar com onpecto interpretativo, contextual e pratico social.

No entanto, ler não deve ser concebido "apenas como decolifuato de simbolos grâficas, mas o processo completo e pleno de compreensão e interpretą̧io do mundo que nos rodeia" (Zieger, 1994, p.13).

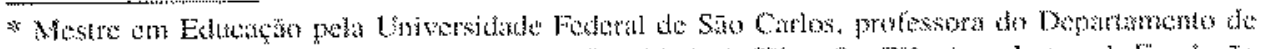

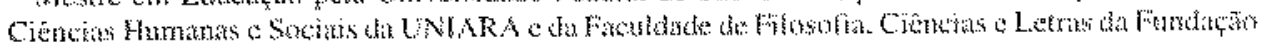

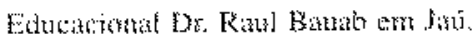


Esse tipo de ensino que ignora o caráter interpretativo acaba formando no aluno a concepção equivocada de que aprender não passa, num primeiro momento, de um processo de memorização, sem nenhum outro valor, nenhum significado ou relação com a prática social.

A prática mecanizada, que aqui questionamos, é reflexo de uma abordagem que encara o conhecimento como algo pronto e acabado; os alunos como seres "nus", sem repertório algum; e o professor como o detentor de todo o saber.

Devemos considerar, porém, que estas idéias estão sendo, do ponto de vista epistemológico, amplamente debatidas no cenário acadêmico científico. As mudanças de concepções que o mundo vem sofrendo nas diferentes áreas do conhecimento, decorrentes dos avanços teóricos e resultados de pesquisas em inúmeros campos científicos, imprimem a necessidade de uma revisão das concepções próprias da área educacional, destacando-se a de conhecimento, de educação, de professor, de aluno...

Com estas preocupações em mente, muitos profissionais da área vêm debatendo sobre a situação da educação diante do panorama geral das ciências marcada por uma crise paradigmática. Nessa perspectiva, o conhecimento começa a ser concebido como sendo uma rede de relações e não mais como algo estático, fragmentado. A era do particular fez-se, em seu período histórico, necessária para que as especificidades fossem compreendidas enquanto tal, mas, superada essa etapa, o que se torna emergente é a superação de visões estanques e compartimentadas. O momento é, pois, o de interação/inclusão já que nesse período não mais se fazem necessárias divisões extremas para que o mundo seja compreendido, vivido e transformado.

Dentro dessa concepção de mundo/conhecimento, o aluno não é mais visto como um "copo vazio" a ser preenchido com/por esse conhecimento, mas sim como um ser capaz de recriá-lo, e o professor, por sua vez, não seria mais aquele mero transmissor de conhecimentos, mas aquele responsável pela condução de tal processo. O ensino aqui não está ligado exclusivamente à transmissão de conteúdos, mas também ao comprometimento com um processo que objetiva criar condições para que seja possível ensinar algo novo, novas relações sem descuidar, no entanto, de tratamentos diferenciados ao "patrimônio" (teórico e empírico) historicamente acumulado. Dessa forma, o professor seria responsável por estruturar um ensino no qual os alunos possam fazer sínteses, generalizações, ampliações, pois é aquele quem, por um lado, trará para a sala de aula situações problemas, quem criará conflitos, contradições, dará contra-exemplos e, por outro lado, possibilitará a exploração do repertório ou das experiências dos alunos.

Nessa perspectiva, o trabalho docente permitiria a inserção do aluno num mundo repleto de relações podendo, assim, contribuir para a formação de indivíduos autônomos, críticos, cooperativos, criativos, éticos, etc.

Contudo, o que se vê ainda e com uma freqüência significativa é uma prática educativa fragmentada, distanciada das necessidades escolares hoje emergentes, dando primazia às técnicas em detrimento do raciocínio. 
Algumas inciutivas que se prestaram a romper com este quadro tomaram rumos opostos, tăo ndicais quitnto os merions. Em nome das ideias e porques

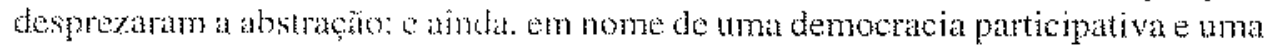
abertua difacional, ignoram a importancia das regras, dos limites e da disciplina."

Em sintese, este 6 o centrio educacional. Por mon lado temos o radicalismo mecuncista formando uma gernăo de subnissos e, por outro, encontramos a anarquia em deconencia da fata de ética definç̧oses de papéis no espaco escolar.

Observamos, portabto. a importancia de se buscar um equilíbrio onde a liberdade, a democracia. a constnçĩo de conheomentos possam ser aliada as abstrocoses aos conhecimentos socialmente elaborados.

\section{Prática educativa e formação de professores}

Historicamente assistimos a um verdadeiro inquêrito onde a cada periodo tendese culpar um ou ouro pela suagão de fracasso no processo eductiona. É bvio que nio quer mos agona contenar o prolessor considerando-o pivô das maledicencias escolares. I preciso observar o problema com protundiande, tomando-se como referencia lodas as dimensoes que o configuram.

Neste conkexto, temos de impreterivelmente, refletir sobre a fommăo dos professores. Este nāo é un tema simples de se abordar, principalmente, porque, quando fadamos de professores, fakamos, antes de tado, de seres humanos con caracteristicas proprias com visöes de mundo. com identidades construidas historicamente. Nă podemos ignorar a pessoa e, com uma falsa neutralidade, tentamos falar do prolessor.

Oprofessor é uma shotese de tudo oque ele é como pessoa, tomando-se cono

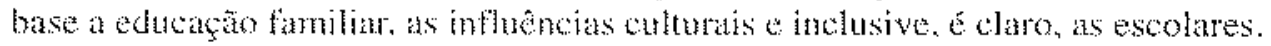
Sendo assim, o curso de graduçăo năo determina ünica exclusivamente as características es pressupostos gue guarato a pratica docente.

Dificimente esse professor receber, nas instancias educativas que o intrenciaram, uma formaga voltada para as questoes que se antuciam diante de um novo paradigma. Parece obvio, entāo que ele näo saba lidar, con certa polidez, com questöes tĩo complexas como as de interdisciplinaridade, construtivismo, etc. F. claro, ele sempre viu o conhecimento como al ge fragnertado a, de uma hora para outra, queremos que ele nuo apenas acredite em, mas lide com o conhecinento como uma rede de relaçoses.

Do ponto de vista prático, parece, entäo, que alguns equivocos estão sendo cometidos. A excola. em nome de uma perspecliva metodological altemativa, insiste em se anodenominar consmutivisth prodty materais "ditos" construtivistas. No entato, continu trabahando com o professor que ainda vê o conhecimento em

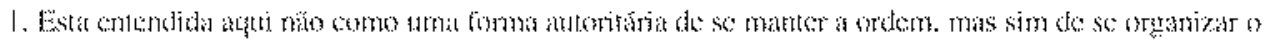

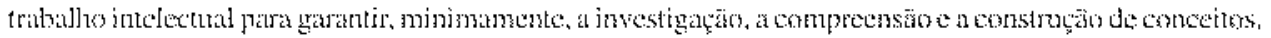


compartimentos isolados. Será que o material didático por si só garante uma metodologia altemativa?

Este deve ser um dos equínocos mais primários, pois, se assim o fosse, não precisarianos mats fomar prolessones. Bastaria que um bom a tor estudasse o material e encenasse sua peça. É preciso ver a profissīo docente como uma cadeia de atividades que pressupoem, sobretudo, una produçāo. Caso contrúrio. estariamos sendo contrajitórios. Parece un tanto quanto antagonico o fato de impelir o professor a reproduzir. en sala de aula, um material que petmitiá a construğio de conhecingento.

É por esta maño que presumimos ser este o momento dese criar siruaçoses para que esse docente possa refletit, examinar, reelaborar suas concepços. Não basta que novas visoes de edraçäo sejum brilhantemente produzidas pela academia, of preciso que o professor tenha condiçös para questionar, por ele mesmo, seus valores e. suas açōes.

Esse exercício de repensar a prática educativa ná é desenvolvido de forma consistente nos cursos de licenciatura principalmente porque nāo temos hoje uma estrutura que permita ao ahno (futro professor) exerciar a docencia de forma sistemática anda dumante o curso e em decorencia, não se pode delimitar com precisăo as diffculdides que serāo enlrentadas. Isso porque os cursos de fomacto de protessores nâo têm como prever, pura assim poder trabalhar, a muliplicidade de eventos que se manifestam implicia ou explicitamente durnte a atidade docente.

Alguns autores vem anumbiando que "a prálica pedagógica vem sendo considerada o eixo central da fomaço docente e espaç próprio de construçio de suberes pedagógicos, constituindo-se em categorias de atividades que ocorrem em situaçoes problemáticas que nunca säo ils mesmas, requerendo análise e interpretação por parte do professor." (Chakur. 1994, p.2).

Seguma este raciocíno, muitas pesquisas na área de educação estāo apontando para a importancia da fornaçăo contínua do professor, pois se considera que é no embate da formaçăo da atuaçāo gue o docente desenvolve ama didática pratica passivel de se encaminhar rumo a uma pedagogia alternativa (Martins, Aput André, 1994). 1 sso se justifica por duak vias a primeira considera o fato da formaçăo docente iniciarse antes da academia e permanecer depois dela e a segunda constata que, para pentiar numa formaça docente crítica é necessírio, principalmente pensar ma ą̧o docerute (Santos. 1994).

Nesta mesma linha, outras pesquisas vêm verilicando gue of saberes näo săo constrúfos apenas atraves do cursos de licencianara; văo se constituindo a partir das concepçöes - estas adquiridas no decomer da história de vida do sujeito - e e arravés da experiencia docente ...... esta indubiavelmente adquirida no espaço de representaçes em que vivem os professores: a sala de aula (Penin, 1994).

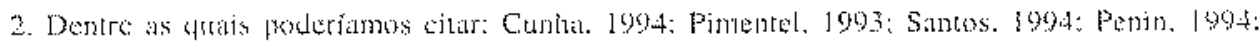

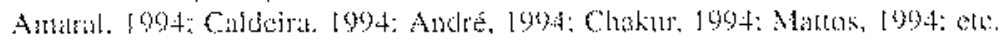


Dessa forma os cursos de fornaçio docente näo fazem mäs sentido se permanecerem apenas no ambilo da graduaçio. Daí a necessidade de valorizamos trakalhos que extejam voltudo para tma formaço docente em serviço.

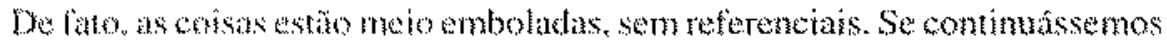
nessa tinha poderianos arolar mutos outros aspecos contradionos implicadores de uma escola, visivetmente em estado de "decomposiçio".

A inenço, por howa s a de problematizar, colocar em pauta alguns aspectos próprios do cenário educacional para pensamos questōes tais como: não seria mats viâvel que o proprio proftssor estivesse repensando sua pratica pedagágica a partir das dificuldades enecsssidades vivenciadas cotidiananente? Por que há uma tendênoia täo forte em se renorat que prolessor pensa? E, en consequiencia a de tentar solucionar os problemas educacionas implantando propostas das guais os próprios molessores silo exelufores de sua produçiso?

Um munça efetiva, verdabim, concrea em sala de ala so pode ser consagrada for prodazida, promovida pelo proprio professor.

\begin{abstract}
:

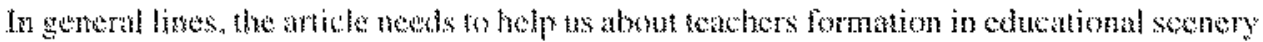

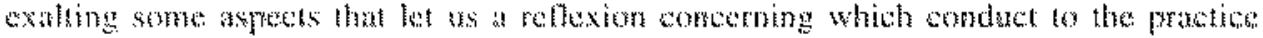

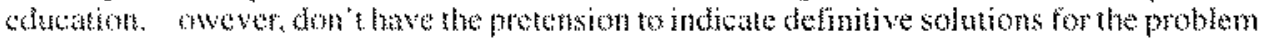
of education. purpose. suplis subsidy lot a discussion around to the necessary retexion on eduation area. having mind. some prohtem implicates in process of education and performance akatemic.
\end{abstract}

\title{
Keywords:
}

Practice edwation, teachers fomation, professional atomomy.

\section{Referênciăs bibliográficticas:}

AMAR, AL, A. L. Os saberes escolares e as escolas nomais: estudos e reflexöes. In: REUNIÄO ANUAL. TAA ANPED, 17, Caxambu, 1994.

ANDRE Murli E. D. A. Processo coletivo de construcâo do saber docente. In: REUNIÄO ANUAL DA ANPED, 17, Caxambu, 1994.

CALDEIRA. A. M. S. A. Prítica decente cotidiana de uma professora e o processo de apropraçäo e constugăo de seu saber: um estudo etnogrítico. In: RELNIÄO ANUA1, DA ANPED, 17. Caxambu, 1994.

CHAKUR, C. R de S. L. Profischonalizaçöo docente: uma leitura pingetana de sua construçio. Im: REUNIAO ANUAL DA ANPED, 17, Caxambu, 1994.

CUNHA. M. I. da O bom professor e sua prática. 3.ed. Campinas: Papirus, 1994. 
MATTOS, C. L. G. de. Etnografia crítica de sala de aula: o professor pesquisador e o pesquisador professor em colaboração. In: REUNIÃO ANUAL DA ANPED, 17, Caxambu, 1994.

PENIN, S. T. de S. A professora e a construção do conhecimento sobre o ensino: algumas mediações. In: REUNIÃO ANUAL DA ANPED, 17, Caxambu, 1994. PIMENTEL, M. da G. O professor em construção. Campinas: Papirus, 1993.

SANTOS, L. de C. P. Formação do professor e a Pedagogia crítica. In: REUNIÃO ANUAL DA ANPED, 17, Caxambu, 1994.

ZIEGER, L. Alfabetizando em Matemática. Importância da construção do significado do número. In: Revista do Professor. Porto Alegre, 10(39): 13-15, jul/set, 1994. 